\title{
AV Fistula Maturation Failure
}

National Cancer Institute

\section{Source}

National Cancer Institute. AV Fistula Maturation Failure. NCI Thesaurus. Code C114780.

Inadequate development of an arteriovenous fistula within three months of creation. 